we can do ; for if a man took scurlet fever in the first week of the year, and gave it to two persons in the second week, and each of these to two others in the third week, and there were nothing to prevent this going on at the same rate, everybody giving it to two persons (and only to two) in the week after that in which he got it himself, which is not at all an unreasonable rate, the people who would have had scarlet fever at the end of the year would be sufficient to populate four million five hundred thousand worlds, with a thousand millions of people each! So you see it is fortunate that something stops the spread of infectious fevers.

"Medical men are also bound to study bygiene because it affords important aids to cure, fresh air, exercise, and a proper diet being of ten more important to a patient than drugs. Remember the words of Rollet, of Lyons. ' Medicine cures individuals, hygien $\theta$ saves the masses,' and the maxim of Hippocrates, "Nature is the healer of diseases." Dr. Corfield then referred to the remarkable evidence given by Dr. Fergusson of the degeneracy of the factory population, and his opinion that want of milk was the chief reason for it; he said that the only way to get milk enough was by the utilisation of the sewage of towns, and that the solution of the sewage question would be the prevention of the degenerncy of the population of our large towns. "But it is especially essential that those who may become medical officers of bealth should be thoroughly acquainted with hygiene; they are consulted on all possible matters relating to the public health, and they must be thoroughly posted in all sanitary matters. Degrees and diplomas are now granted for State Medicine, as it is termed, and the facilities for instruction in the various branches have now been greatly increased in the College by the establisbment of a practical course under the charge of Professor Williamson and myself, and a new laboratory for bygienic analyses is being fitted up and will soon be ready for use."

\section{WESTMINSTER HOSPITAL.}

INTRODUCTORY ADDRESS BY MR. RICHARD DAVY.

THE speaker said that he disapproved in toto of introtroductory addresses, but, at the request of the Medical Council, conformed to custom. Both students and teacher preferred a day's pheasant shooting to hearing or giving an "introductory." As a surgeon, he should cut down his sermon from one hour to fifteen minutes, and his successor might still further reduce the volume of these fruitless harangues. After welcoming his audience, and referring to the changes in the hospital staff, the lecturer drew attention to reform in the practice of medicine and surgery. Far too much stress was laid on the necessity of elaborate teaching. Above all, a young man should be taught self-reliance; his own efforts would then pull him through, just as a vigorous constitution was the mainstay of recovery, independent of elegant prescriptions and repeated visits. University discipline and residence were strongly insisted on; healthy tone and lifelong friendships were acquired by this training, in lieu of an entire want of control now felt by hospital teachers over their pupils, and the acquaintance of these young men from the country with interestingly repulsive specimens of shark (squalidos), known as London landladies. The payment and honours conferred on medical men were next criticised: their salaries were simply miserable; bospital physicians and surgeons were for the most part unpaid; Poor-law officers most piteously; surgeons in the services very badly; and young practitioners not at all. For seven years' hard work at the St. Marylebone Dispensary he bad received one guinea, and a very distinguished London assistant-physician had found that his salary equalled that earned by the man who put the skid on the omnibus wheels at Holborn-hill. He considered that gratuitous work and its consequent dignity were subjects worthy of woman's consideration, and that ladies desirous of occupying a congenial sphere in the profession might ease the men's shoulders from upholding the work and dignities of unpaid appointments. Mr. Davy challenged the authorities to show reason why ancient coroners should call upon qual fi 'd house-surgenns and physicians to give their eviden e without fee. Why should the Registrar-General or Con missioners in Lunacy expect skilled services for nothing? The lesturer warmly supported the Contagious Diseases
Acts, and was pained at the nonsense which had been let off over vivisection. Practical experiments were as important to medical men as to the Royal Artillery on Dartmoor. In conclusion, he advised everyone to resign at once any and every thought of becoming a medical man unless he possessed three qualifications:-18t, independence; 2nd, an aptitude for, and love of, the profession; $3 \mathrm{rd}$, the readiness to pay a heavy premium in this world for his prospects of reward in the next.

THE

\section{TREATMENT OF SECONDARY AFFECTIONS} OF THE HEAR'T.

\section{BY J. MILNER FOTHERGILL, M.D., M.R.C.P.,} JUNIOR PHXSICIAN TO THB WHST LONDON HOSPITAL.

$$
\text { (Concluded from p. 446.) }
$$

IT will perhaps best illustrate the subject of this paper to give one or two typical cases; and then to consider the points of diagnostic importance to be attended to in order to recognise secondary affections of the heart, and to dis. criminate between them and primary affections.

In the latter part of July, 1874, a retired Indian medical officer called on me and asked me to visit his wife. Being engaged that day, and finding it impossible to see her till the morrow, I made inquiries of the gentleman as to her condition. They were old friends of mine, and I knew the lady to be gouty, though she had never had a regular attack of gout in any of her extremities. He told me that his wife had got intermittency of the heart; that it had come on quickly, it not being more than ten days since it was first observed, and that it occurred every third beat very rhythmically. This did not look like true cardiac failure. On inquiring into the other characters of the pulse, he stated that the two beats betwixt each intermission were strong and well sustained. This was an important point, and cleared the diagnosis very satisfactorily. I felt no hesitation in giving it as my opinion that the intermittency was gouty in its origin. To some readers this may seem a bold diagnosis and an unverifiable hypothesis; but it was warranted by the symptoms and vindicated by the results. I gave him a prescription containing iodide of potassium and bicarbonate of potash, in buchu; ordered a slop diet and rest in bed until I could see her the next day. On visiting her the diagnosis was confirmed. The intermittency was already less regular, was no longer rhythmical, and the patient felt better for the treatment. In five days the intermittency had fled and the patient felt almost well, and in a few weeks all sense of illness had disappeared under a combination of iron and alkaline waters. Since then this lady has passed through a sharp attack of bronchitis without any evidence of cardiac debility. In forming the diagnosis in this case, I should not have felt justified in being so positive if previous acquaintance with similar cases had not prepared me for such a conclusion.

At that time I had another lady under care who had suffered repeatedly from suppressed gout, and been under various practitioners, all agreeing in their diagnosis. In this case there was much palpitation, attacks occurring most frequently during the night, when the sensation was that the heart was about to stop altogether. Under a restricted diet, nitrogen being but sparingly admitted, and potash with buchu being administered, great relief was experienced. It was, however, found impossible to get the patient to continue the restricted diet for long, and resumption of the usual dietary and neglect of the medicines always brought back the cardiac trouble, which went off on once more following out the treatment.

Mr. C-_, a literary man of much mental activity, consulted me about his beart. He suffered from attacks of dyspncea, giddiness, and oppression over the heart, which were increasing in force and frequency. There was also numbness down the left arm. This gentleman's father had died of angina pectoris, and he was much alarmed at his symptoms. It appeared that a few weeks only before the consultation he had been in the country and taken severe 
and prolonged walking exercise without any symptoms of cardiac weakness. He was gouty, and had recently been living well, eating much animal food under the idea that it was the most strengthening diet. A restricted dietary, with potash and buchu, soon relieved him from the attacks, and he has contiuued well since. This is now fourteen months ago, and be has had no return. When not feeling quite well, he falls back upon his medicine, which soon puts him to rights.

Mr. B-, a retired chemist, consulted me for similar attacks, and under a like treatment he also got relief forthwith, and has since been well as regards his heart troubles.

These are a few out of a number of cases which have come under my notice, in private and in hospital practice, which have presented like features, and which bave got well under similar treatment. This latter is a point of much importance. Potash, as a muscle poison, in all its forms, is a powerful depressant of the beart, according to Botkin, of St. Petersburg; and Ringer speaks of the depressing effects of the iodide. If the heart had been primarily at fault there is every reason to suppose that the treatment would have been pernicious rather than beneficial; but being only secondarily affected, the effect of these measures, in improv. ing the depuration of the blood and so doing away with the heightened blood pressure, was to relieve the heart and to disperse the symptoms of cardiac adynamy. It is not easy to say how the buchu acts in these cases. It has been said that it increases the amount of solids in the urine ; but this, again, is denied. Certain it is that, in practice, the addition of buchu seems to add to the efficiency of the potash. It forms, at any rate, an agreeable vehicle, and goes well with iron. It is good practice to substitute potassio-tartrate of iron for the iodide of potassium on the relief of the symptoms; and this mixture of potash and iron may be continued with advantage, as a tonic, for some time in these cases. It is also desirable to prescribe mineral waters-Seltzer, Vals, Vichy, Couzan, and otbers-as a beverage to be taken permanently. With Marsala, claret, or a little gin or Schiedam, they are agreeable to the palate, and act efficiently in helping to remove the products of waste; the accumulation of which forms the condition designated lithiasis, commonly termed "suppressed gout."

The attacks known as gout at the heart are produced by the sudden rise of blood pressure from arteriole spasm and the consequent cardiac embarrassment. It is easy to see how severe and even fatal attacks may be thus induced: Disease of the aortic valves is also common in gouty individuals, and the secondary affections of the heart may be complicated with primary disease of that organ; and in these cases it becomes necessary to discriminate between the two elements of the case. It becomes desirable, in cases of combined secondary and primary heart trouble, to combine the treatment of each form, and to fit complex treatment to complex maladies.

In forming a diagnosis of secondary affections of the heart, and determining that the heart symptoms are really consequential to some prior and causal disturbance of the circulation, there are several points deserving of special notice.

1. The attacks of dyspncea, palpitation, or sensation of beart stoppage are not induced by effort, but come on independently of any exertion. They not uncommonly come on during great quiet, and even when lying in bed. Not rarely they permit of active exertion, which does not tax the heart in this class of cases; whilst in primary affections of the heart effort always - or almost al ways, to be very safereveals the existing adynamy. A little active movement will render the evidence of true heart failure more pronounced, as I remember well in an old man who used to take a sharp turn round the honse to illustrate how exercise made his beart palpitate; while in pure cases of secondary heart affection exertion does not induce the attaoks.

2. The pulse is not that of cardiac debility: even when the pulse is very irregular there is a force about it which resists compression, quite different from the irregular com. pressible pulse of cardiac dilatation. There is indeed the sustained pulse of high blood-pressure in the midst of the irregularity, or intermittency. Not rarely, if the arteries are atheromatous, the irregularity is found along with a full sthenic and powerful pulse-a combination, once well noted, ever afterwards recognisable, though not to be described by words. It is a matter of no slight moment to become familiar with the pulse of these conditions. The feeling of the pulse here is not a mere formal matter, but a measure which of ten gives valuable indications and directs the line of investigation to be pursued.

3. The first sound of the heart is good usually-loud clear, and of fair intensity. It preserves its muscular sound and is not simply valvular, and does not approach the second sound in character. When there is much bypertrophy the first sound is loud and long. Not uncommonly there is some reduplication of the first sound from delay in the contraction of one of the ventricles. On examination of the heart, it is found acting well and not giving evidences of lack of power. The rhythm may be disturbed; but there are not evidences of heart failure accompanying the disturbed rhythm.

4. The second sound of the heart is accentuated. This is a most important diagnostic point. In primary disease or debility of the heart this symptom is never found;* in the forms of heart trouble which are the consequences of some prior disturbance of the circulation, causing a rise of blood pressure in the arteries, this objective symptom is never wanting. The accentuation of the second sound will, of course, be more or less intense according to the rise in the blood pressure. It may be found at both the pulmonary and aortic valves. It is most distinct, however, at the aortic valve; and heard most loudly at the second right costo-sternal articulation. The semilunar valves are closed by the recoil of the elastic arteries; if then the tension in the arteries is increased, these valves will be closed with unwonted force, and their closure produces an accentuation of the normal sound. Such accentuation is ever found in the pulmonary valves when the mitral valve is diseased: here it is the measure of the engorgement of the pulmonic circulation. When heard at the aortic orifice this accentuation may be associated with aortic aneurism (Begbie), with general paralysis of the insane (West Riding Asylum Rep., 1873), or with the general rise of blood pressure in lithiasis. It is easy to separate these conditions. The Germans attach great importance to this objective symptom, as might be supposed from their general high estimate of signs whose existence and explanation are clear and rational. If the second sound is produced by the recoil of the elastic arteries, when the blood pressure is abnormally high this sound will be unusually loud. There is no ambiguity about a sign of this kind, and its logical clearness endears it to the Teuton mind. Hence they attach great and deserved importance to this accentuation of the aortic second sound in the diagnosis of chronic Bright's disease; under which circum. stances a rise in the blood pressure and this indication of it are most commonly found.

By such means, then, are secondary affections of the heart to be distinguished from the primary affections of that organ. If the examination be made with sufficient care, and there also exist a fair comprebension of the subject in its entirety, the practitioner should be able to discriminate the exact form of the affection; and if there be also some actual cardiac debility, to allow for it, both in the diagnosis and in the selection of the line of treatment. Having decided that the cardiac troubles are secondary to some primitive affection of the vascular system, causing a rise of blood pressure, the principles of treatment are as follows:-

1. To improve blood depuration by removing the accumulated products of nitrogenised waste; and this can be best accomplished by a combination of measures. First : to cut down the nitrogenised elements of the food to the minimum, so as to lessen the production of waste products. Second: to administer potash or lithia in combination with vegetable diuretics, and so to aid in the elimination of waste by the kidneys. This latter action will be assisted by throwing the skin into action.

2. If there be present a certain amount of cardiac debility, the depressant effects of the above treatment may be met by the administration of digitalis along with them.

3. After immediate relief has been furnished it is desirable to administer alkalies together with iron for some time. Contrary to what is indicated in primary debility of the heart, the diet should be restricted, and the amount of nitrogen in the ingesta should be small t

* This accentuation is not to be confounded with the brief but loud second sourd of unfilled vessels; of cen this is only pulmonar:

+ The recent papers of Parkes, as to the effect of a uon-nitrogeniced diet upon the blood pressure, lowering it very remarkably, are very suggestive as to the diet of persons suffering from secondary affections of the heart. (THE LANCET, May 23rd and 30th, 1874.) 
4. Active exercise in these cases is rather indicated than otherwise, and the increased oxidation induced thereby is beneficial, while the exertion does not act injuriously upon the heart.

The neurosal affections of the heart require a treatment of their own. What the indications for treatment are in this class of diseases will need another and concluding communication.

Lower Seymour-street, W.

\section{ON SOME EFFECTS OF MODERN RIFLE PROJECTILES.}

By Dr. HUGO SENFTLEBEN,

IATH STAFF-SURGFON WITH THE 61ST PRUSSIAN INFANTRY IN FRANCR.

IT is a well-known fact that each party in the late Franco-German war charged the other with using explosive bullets for small arms, in violation of the treaty proposed by Russia and accepted by most of the European powers, which forbade any explosive projectile weighing under one pound. Even the Prime Minister of Germany made such allegations the subject of diplomatic representation; and not only the French newspapers brought similar accusdtions against the Prussian soldiery, but $I$ had myself, unluckily, to experience reproaches of the same kind on the part of French officers, when, after the last of the bloody encounters with the army of the Vosges, a Garibaldian colonel detained me as prisoner of war because I had remained single on the battle-ground to attend upon the wounded of both parties.

$I$ have endeavoured in vain to find any scientific reasons stated in support of those angry recriminations, though I am not at all surprised to have heard them repeated by soldiers who saw the effect and judged from the appearance of hostile rifle projectiles when in the act of striking. It is, however, the great force of propulsion which modern rifles give to their elongated bullets, and the much more frequent skirmishing in mountainous districts, and the village and town fights, which offer numerous occasions for ricochets and splitting of projectiles, that give us an easy and natural explanation for many cases of reputed violation of a now established international law. The very destructive effects which are made in the animal body by the explosive bullets used in the chase of large game prove the wisdom and humanity of such a law; and when the journals of Lyons announced the arrival of a renowned lion-hunter from Algeria amongst Garibaldi's sharpshooters, the news was a little trying to those of his enemies who believed in the rumours of French faithlessness to the contract. But during the three days' hard fighting around Dijon in January, 1871, and at the subsequent surprise in Prautboy, I have seen nothing that could confirm suspicions of the kind, though I frequently noticed balls that struck a wall split up and dispersed in pieces, as if they were exploding, like liquid metal falling from a height on stony ground.

The aptitude to change form and to break up into irregular and jagged fragments when hitting on a stone or metal, as steel, brass, or iron, depends not only ( $n$ the initial velocity and the consequent strength of impact, at even longer distances, but also very materially on the composition of the ball. Pure lead, as it was used with the Austrian Lorenz rifle in 1866, the German needlegun of Dreyse, and the old French Minié muzzle-loaders, or those converted on the Snider principle into breech-loaders $a$ la tabatière, splits much more easily than the bullet of the Chassepot or otbers of the modern breech and magazine loaders, which are hardened by an alloy of tin (the Henry-Martini projectile, e.g., contains 1:12 of lead). The latter pentrate more easily the tissues of the animal body, and shatter-if their force of propulsion (i. e., initial velocity) and weight be equal-more readily the bones without changing their form, as Professor Long more had sagaciously pointed out beforehand ("On the probable Surgical Effects in Battle in case of the Employment of Projectiles of a more Elongated Form"-Army Medical Rep., vol. v., 1865). They resemble in this respect grajeshot, which is so much more destructive than the old round musket-ball. The reputed destructiveness of the Dreyse rifle projectile-the Pruesian " langblei" (elongated lead)-depended, on the contrary, on its greater propensity to break up and hurt through its sharp-edged débris. I remember the case of an Austrian foot soldier from Servia, who was wounded at Koeniggraetz by a "langblei," and, with a fractured tibia, had been at some hospital in Saxony. Three weeks after the battle be cawe under my care at Berlin, walking into the ward with a stick in company with others. For some days he could scarcely be kept in bed until he began to complain of violent pains and repeated hæmorrhage set in. There were two openings in the leg at the middle of the calf, showing entrance and exit of the ball. Four weeks after receipt of the injury I was called to see him, when he was nearly pulseless from loss of blood. An incision led into a large hollow filled with clots, frag. ments of bone (the tibia was broken through), and some sharp-pointed pieces of lead. The circular amputation below the knee, which I performed immediately, saved the man's life, who made a very quick recovery; and I found the posterior tibial artery injured and ulcerated for the length of nearly an inch by contact with those spicula of metal, which but for their dangerous sharpness would have been comparatively harmless. There are plenty of similar cases on record. The power of the hardened Chassepôt bullet may, however, act with very great effect on a bone without causing any deformity of the projectile. I saw a remarkable instance of this when in garrison at Belfort during the armistice. The surgeon in charge of the German soldiers wounded during the siege consulted me about a Landwehr artillery-man, thirty-nine years old, who had in a night assault been struck by a Chassepôt projectile, which entered his shoulder joint from above at very short distance, and left the arm at the lower insertion of the deltoid muscle, with. out losing its shape. Two months had elapsed, and the patient was nearly exbausted by septicæmic attacks from destruction of the joint, which I found transformed into an abscess discharging incompletely through two or three fistulous openings at the usual points. I made an incision through the wasted deltoideus, emptied several ounces of stinking pus, and, on introducing my finger, found the articular head of the humerus broken off at the anatomical neck and forced like a wedge between the two portions of the longitudinally cleft diaphysis, which, being only partly divided, acted like a pair of pincers, and kept the detached frugment entirely jammed. With some difficulty I extricated the latter; there was no other necrosed bone, and the patient did so well that he was soon afterwards sent to Germany. The very elasticity of the fissured shaft proved that the fracture and impaction of so small a portion as the anatomical head was not due to morbid fragility of the osseous tissue, but to the extraordinary propelling power of the hardened bullet. So I have observed a Chassepôt penetrate both knee-joints, crushing the condyles, and cut it out unaltered in shape from under the skin of the outer joint

Where greatly deformed or broken projectiles are found in wounds, a doubt may arise whether such deformation or breakage be caused by the ball expending its force on the bone, or whether it entered the body after rebounding from some harder aubstance, and becoming deformed or split up before striking the osseous tissue. The appearanee of the entrance opening seems to be less important for deciding this question than the shape of the metal itself. Even soft lead bullets will seldom acquire so jagged and torn forms by impact on bone as they present when ricochetting from some harder metal or stone. Two very instructive cases of this kind came under my notice after the battle of Woerth, when some of the French wounded were sent up by rail to the fortress of Minden, where I was engaged in establishing a reserve hospital. Both soldiers had the humerus broken at its upper third in a very similar manner-a simple borizontal fracture with the projectile lodging. One was a Cuirassier belonging to those famous but unfortunate squadrons of Reichshofen, the other a little, fat, old womanlike Zouave, who lamented loudly when I cut out the ball, whereas the Norman horseman looked on the same operation with sombre and stoical mien. The unburied masses of lead were much like each other, quite shapeless, like a piece of molten metal thrown into water and suddenly cooled; the Cuirassier's was rather more flattened and jagged. Had these Frenchmen received the Prussian 